\title{
ISSN Roundtable: FAQs About the ISSN
}

\author{
Jose Antonio, Marc Gann, Douglas Kalman, Frank Katch, Susan Kleiner, Richard Kreider, and Darryn \\ Willoughby
}

\section{MISSION STATEMENT OF THE ISSN}

The mission of the International Society of Sports Nutrition is to be recognized as the leading professional organization in the study and application of sports nutrition. The ISSN is dedicated to promoting and supporting the study, practice, education, research and development of sports nutrition and the sports nutrition profession. All information disseminated by the ISSN is unbiased and scientifically supported. Journal of the

International Society of Sports Nutrition. 2(2):1-3, 2005

\section{Q: HOW AND WHY DID THE ISSN GET STARTED?}

Richard Kreider, Ph.D. - The idea for the ISSN came from a discussion that a number of practicing sport nutritionist's and researchers had while attending the Sport and Cardiovascular Nutritionist (SCAN) meeting in Chicago, IL in the spring of 2003. Several colleagues (who soon became board members) participated in a round table discussion with members of SCAN. Concerns were raised over frustrations that practicing sport nutritionist's and researchers were not well-represented by other academic groups and societies and that efforts to professionalize sport nutritionists through these organizations had not been too successful. There was concern over a lack of criteria and standardization of coursework among academic programs focusing on sport nutrition; the need to credential sport nutritionists; the need for licensure; the need for the dissemination of unbiased sports nutrition information; and, long-term job prospects. During discussions at dinner that evening with a group of about 40 prominent sport nutritionists, Dr. Sue Kleiner said "Why don't we just start our own organization? With the support of those in attendance, Dr. Joey Antonio and Dr. Doug Kalman began work on developing the ISSN. Within a few months, the ISSN was born.

Jose Antonio, Ph.D. - The primary reason the ISSN was formed was to provide a forum dedicated solely to the rapidly growing field of sports nutrition. There is no single academic society that is dedicated to this field. The networking opportunities for students, professors, as well as industry professionals are truly unique with the ISSN. Many academicians complain of the 'lack of regulation' or the 'lack of evidence' regarding the safety and efficacy of the entire sports supplement category. Yet, many of these same academics do nothing about it. The only way to change and improve a category is to get scientists involved with industry. Industry needs the expertise provided by sports nutrition PhDs who do research. Without this expertise, many of these companies are merely marketing firms pretending to know the difference between a Life Cycle and the Krebs cycle. The ISSN provides a platform where excellent science can meet the student, the practitioner, the manufacturer, and the athlete.

\section{Q: WHAT NICHE DOES THE ISSN FILL?}

Douglas Kalman, M.S. RD - The ISSN serves to be a resource, an educational association of various level academics, coaches, trainers, athletes, administrators and food scientists who either work directly in or dabble in sports nutrition at all levels from children to professional adult athletes.

Richard Kreider, Ph.D. - Until the ISSN was started, sport nutrition research and tutorials were presented at meetings for organizations who had some interest in exercise and sport nutrition but were not dedicated solely to the field of sport nutrition. Those interested in sport nutrition attending those meetings may have participated in various interest groups but the groups were just a small minority within a larger professional organization. Since sport nutrition was not the major interest of these organizations, efforts to offer education sessions, academic accreditation, certification, and/or licensure were limited. The ISSN offers an opportunity for practicing sport nutritionists to meet, discuss the latest research and practical methods in the field, and a framework to begin professionalizing the field of sport nutrition. It also provides an avenue to provide unbiased educational material to the scientific community, nutrition industry, and public.

\section{Q: IF YOU EARNED THE CISSN (I.E. THE SPORTS NUTRITION CERTIFICATION}




\section{FROM THE ISSN), WHAT DOES THAT SIGNIFY TO THE CONSUMER AND TO THOSE IN ACADEMIA?}

Douglas Kalman, M.S. RD - The CISSN is the premier certification for anyone who wants to be known as a well-trained sports nutritionist. This test and certification process enables the consumer and other health professionals to know that the person who is designated as a "CISSN" has core competencies in basic exercise physiology, integrated physiology, bioenergetics, nutrition, sports psychology and other pertinent areas to any real sports nutritionist.

Darryn Willoughby, Ph.D. - It demonstrates an impressive level of knowledge and competence regarding various aspects relative to exercise and sports nutrition. The CISSN is in class of its own regarding the content and rigor of the exam. Furthermore, the questions on the exam are specific to pertinent issues of exercise and sport nutrition where many other exams seem to fall short.

\section{Q: WHAT ARE YOUR THOUGHTS ON THE BCC-ISSN (BODY COMPOSITION CERTIFICATION) PROVIDED BY THE ISSN?}

Darryn Willoughby, Ph.D. - The BCC-ISSN is a very impressive, practical, and intuitive endeavor in which one's knowledge and exercise and sport nutrition is specified even more as individuals become educated in the various aspects surrounding body composition assessment and interpretation.

Frank Katch, Ed.D. - The BCC-ISSN is unique in the industry - it establishes a standard of excellence to assess body composition. The BCC-ISSN includes the exclusive Body Image ${ }^{\mathrm{TM}}$ Analysis System (BIAS) for total body composition assessment via simple height, weight, girths, and skinfolds that are entered into a user-friendly Internet database. A personalized output report accurately estimates body fat, pounds of fat, fat-free body mass, lean to fat ratio, BMI, basal energy requirements, and total calorie requirements. Earning the BCC-ISSN means the individual knows how to reliably and validly assess body composition related to weight loss and weight gain (body weight management). Such individualized assessments provide realistic goals about how clients can best achieve an "ideal" balance between the body's fat and non-fat compartments, and how these components change during exercise and training regimens of different durations and intensities. Also, a proper body comp assessment delivers an important message to clients about the potential need to alter lifestyles, particularly to increase the quantity and quality of daily physical activity regardless of weight loss goals. Those who achieve the BCC-ISSN will have a first-rate certification to meet clients needs related to body composition and health, fitness, obesity, weight control, and training.

\section{Q: DO YOU NEED TO BE AN RD TO PROVIDE SPORTS NUTRITION ADVICE?}

Douglas Kalman, M.S. RD - The moniker "RD" or Registered Dietitian is one to be appreciated and thought of as a national Registration in nutrition. However, the RD status on its own does not indicate that one has a specialty within nutrition (food service professionals are RD's, geriatric nutritionists are RD's, etc.) however it does indicate a general knowledge in a wide arena of food and nutrition related topics. Sports nutrition is a small sector, a small precise slice of the nutrition pie, if you will. The CISSN is an official recognized international certification that clearly denotes a field of expertise in sports nutrition; therefore it is the preferred professional achievements. Registered Dietitians who are CISSN's have a great complimentary professional background, as do anyone with an advanced degree in exercise physiology or related areas once they become a CISSN.

Susan Kleiner, Ph.D., RD - Advice in nutrition is being given by those without any training in nutrition on a nationwide basis, every day. The goal of developing state licensure in nutrition was to limit the practice of nutrition to those professionals whose training placed nutrition within their scope of practice. Personal trainers, coaches, exercise physiologists, exercise scientists and sports medicine professionals work closely with patients and clients on a weekly or even daily basis, and they are asked sports nutrition related questions regularly. The CISSN provides an educational standard by which these professionals can safely, accurately and legally work within their scope of practice. It also enhances the knowledge base of the RD, a certification already recognized as the standard in nutrition practice.

Marc Gann, Esq. - From a legal perspective, each state has the authority to legislate or otherwise regulate who may provide nutritional advice. Many states have no specific statutes or regulations as to the dispensing of such advice; while some, such as Ohio and Florida, permit only Registered Dieticians to dispense nutritional advice for monetary gain. However, the CISSN would certainly provide any oversight agency with a significant degree of 
confidence in the ability of the individual providing the advice. One should certainly check the laws of his or her state to determine whether such acts are permissible.

Q: WHAT IS PERHAPS THE GREATEST SINGLE BENEFIT PROVIDED BY THE ISSN?

Jose Antonio, Ph.D. - The single greatest benefit the ISSN provides is the networking opportunities for up and coming nutritionists, dietitians, and exercise physiologists to meet the premier researchers in the field as well as CEOs, Presidents, and Marketing Directors of some of the largest food and supplement companies in the world. Furthermore, as the only academic society dedicated to promoting the science and application of sports nutrition, we maintain our focus and are not trying to be 'all things to all people.' 